\title{
International trends in pedestrian injury mortality
}

\author{
I G Roberts
}

Injury Prevention Research Centre, Department of Community Health University of Auckland Medical School, Private Bag 92019, Auckland, New Zealand

Correspondence to: Dr Roberts.

Accepted 14 September 1992

\begin{abstract}
Trends in pedestrian injury mortality for children aged 0-4 and 5-14 for England and Wales, Denmark, Sweden, the USA, and New Zealand were examined from 1968 onwards. While there has been a reduction in the pedestrian mortality in all these countries, there are striking international differences in the extent of these reductions. Denmark has achieved the greatest fall in mortality with the smallest decrease seen in New Zealand. Countries which have experienced major decreases in pedestrian mortality are distinguished by having placed greater emphasis on environmentally based prevention strategies rather than pedestrian skills education.
\end{abstract}

(Arch Dis Child 1993;68:190-2)
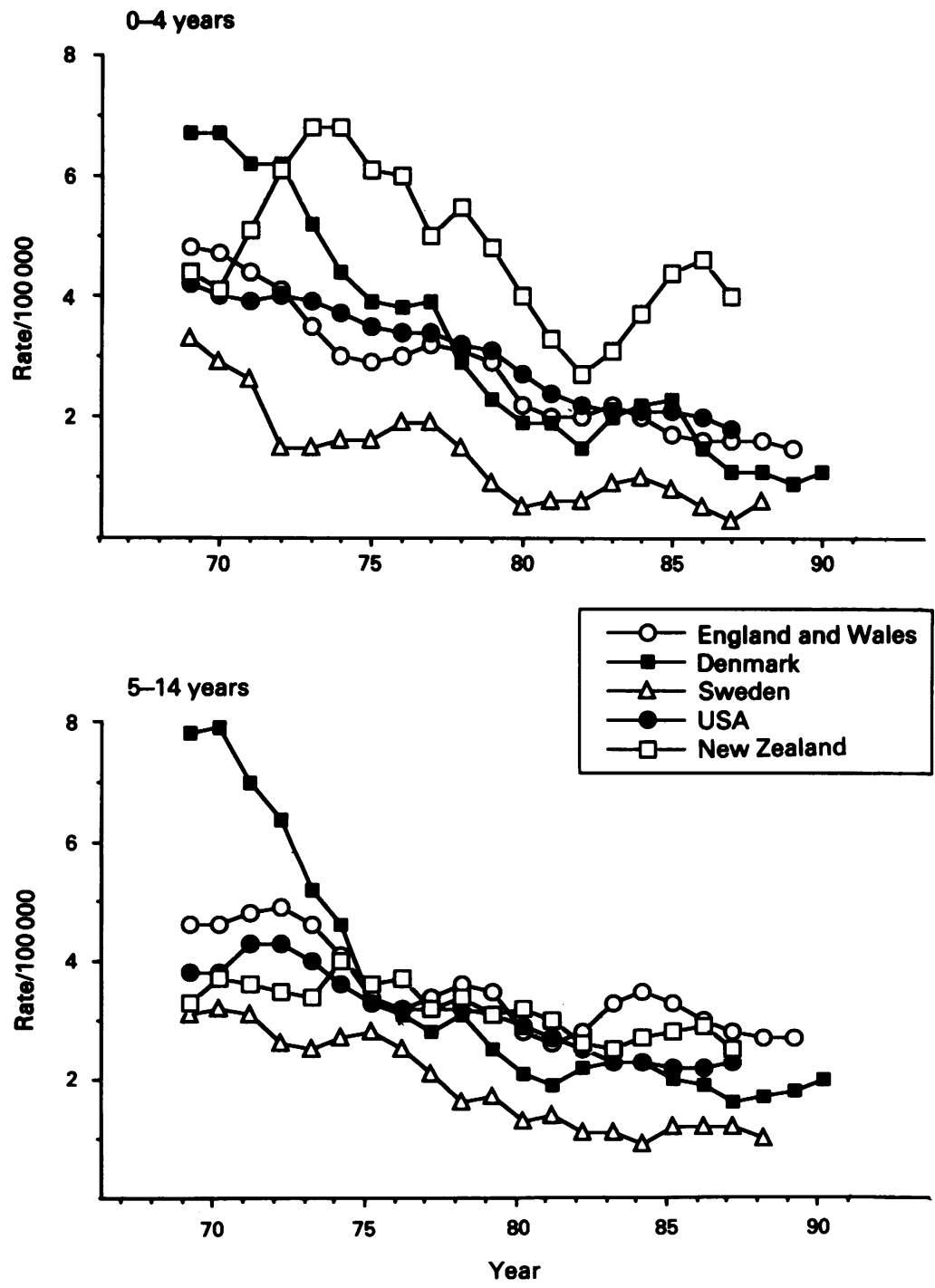

International trends in pedestrian injury mortality for ages 0-4 and 5-14 from 1968 onwards.

Pedestrian injuries are a leading cause of childhood mortality. ${ }^{12}$ Each year in England and Wales approximately 230 children are killed in pedestrian-motor vehicle collisions. ${ }^{3}$ For the children who survive the injuries are often severe. A North American study found that $24 \%$ of children involved in pedestrian motor vehicle collisions required hospital admission. ${ }^{4}$ Serious head injury is common with high levels of residual disability. ${ }^{56}$

Over the past two decades a number of different approaches to the prevention of child pedestrian injuries have been tried in different countries. Usually these strategies are implemented at the national level as part of a countries road safety policy, for example, the Green Cross Code in the UK. International comparisons of child pedestrian fatality rates may therefore provide some insight into the relative efficacy of the different strategies adopted. In this study international trends in child pedestrian mortality are examined and these trends are considered in relation to the types of preventive strategy employed.

\section{Methods}

Pedestrian injury mortality rates (ICD $9 \mathrm{E}$ code 814.7) for children aged $0-4$ and 5-14 were obtained for England and Wales, Denmark, Sweden, the USA, and New Zealand from 1968 until the most recent year for which these data were available. Data for England and Wales were obtained from the Office of Population Censuses and Surveys, for Denmark from the Danish Council for Road Safety Research, for Sweden from Statistics Sweden, for the USA from the Centers for Disease Control, and for New Zealand from Health Statistical Services published data. To reduce the influence of random variability and give a clearer impression of overall trends, three year moving averages were calculated and shown graphically. Specific year comparisons were made for 1987 , the most recent year for which data were available for all the countries studied.

Results

The trends in pedestrian injury mortality for children aged 0-4 and 5-14, for England and Wales, Denmark, Sweden, the USA, and New Zealand are shown in the figure. For children aged $0-4$ there were marked international differences in mortality rates with New Zealand having the highest rates and Sweden the lowest. By comparison with Sweden in 1987 the pedestrian mortality rate in New Zealand was $13 \cdot 3$ 
Table 1 Pedestrian mortality in children $0-4$ years in 1987

\begin{tabular}{ll}
\hline Country & $\begin{array}{l}\text { Ratel } \\
100000\end{array}$ \\
\hline Sweden & 0.3 \\
Denmark & 1.1 \\
England and & \\
$\quad$ Wales & 1.6 \\
USA & 1.8 \\
New Zealand & 4.0 \\
\hline
\end{tabular}

Table 2 Pedestrian mortality in children 5-14 years in 1987

\begin{tabular}{ll}
\hline Country & $\begin{array}{l}\text { Ratel } \\
100000\end{array}$ \\
\hline Sweden & 1.2 \\
Denmark & 1.6 \\
England and & \\
$\quad$ Wales & 2.8 \\
USA & 2.3 \\
New Zealand & 2.5 \\
\hline
\end{tabular}

times higher, in the USA 6.0 higher, in England and Wales 5.3 times higher, and in Denmark 3.6 times higher (see table 1). A similar pattern of decline was observed in all five countries over the study period with a marked decline in the early to mid-1970s, a slight increase after 1976 and a further major decline between 1978 and 1982. Between 1968 and 1987 the largest absolute reduction in mortality rates was in Denmark with a reduction of $5 \cdot 6 / 100000$. The smallest absolute reduction was seen in New Zealand with a reduction of $0 \cdot 4 / 100000$. Sweden experienced the greatest percentage reduction in mortality rates $(91 \%)$ followed by Denmark (84\%), England and Wales (67\%), the USA (57\%), and New Zealand (9\%).

For children aged 5-14 years there were again conspicuous international differences in mortality rates with England and Wales having the highest rates and Sweden the lowest. By comparison with Sweden in 1987 the mortality rate in England and Wales was $2 \cdot 3$ times higher, in New Zealand $2 \cdot 1$ times higher, in the USA 1.9 times higher, and in Denmark 1.3 times higher (see table 2 ). There has been a steady decline in mortality rates in all five countries since 1968, although the decline for children aged 5-14 years was less pronounced than that for the $0-4$ year age group. Between 1968 and 1987 the greatest absolute reduction in mortality rates was seen in Denmark with a reduction of $6 \cdot 2 / 100000$. The smallest absolute reduction was in New Zealand with a reduction of 0.8 / 100000 . Denmark showed the greatest percentage reduction in mortality rates $(79 \%)$ followed by Sweden (68\%), the USA (40\%), England and Wales (39\%), and New Zealand (24\%).

\section{Discussion}

The examination of trends in mortality is sometimes complicated by changes in classification conventions for the cause of death. However although in this study cause of death was classified according to the 8th revision of the International Classification of Diseases from 1968 to 1978 and the 9th revision subsequently, the code for pedestrian injury remained unchanged between these revisions. Furthermore for events as unequivocal as pedestrian-motor vehicle collisions it is unlikely that the external cause of injury would be classified differently in different countries. It is therefore reasonable to assume that valid international comparisons can be made for the time period studied.

The data show that although there has been a fall in child pedestrian mortality for children of all ages, there are marked international differences in the extent of these reductions with substantial differences in the most recent mortality rates. In 1987, if England and Wales had experienced the same pedestrian mortality rate as Sweden, there would have been 130 fewer child pedestrian deaths.

While it would be inappropriate to attribute the international differences in pedestrian mortality rates to any specific prevention programme some 'broad brush' inferences may be justified. The most striking difference between Denmark and Sweden, countries which have made impressive strides in the reduction of pedestrian mortality, and New Zealand and Britain, where reductions have been less impressive, is the greater emphasis given to environmental approaches to prevention in the former countries as opposed to educationally based prevention strategies in the latter. ${ }^{78}$ Although all countries have employed both environmental and educational measures to some extent, legislative changes in Denmark and Sweden, which gave greater priority to pedestrians, resulted in a balance of strategies weighted more towards environmental change in these countries. ${ }^{7}$ In particular Denmark, which changed its ranking from having the highest mortality rates in 1970 to being second only to Sweden in 1988, made a major commitment to a programme of environmental change which resulted in lower vehicle speeds in urban areas. ${ }^{9}$ Specifically, local streets were designated as 'living areas' with speed limits of either $30 \mathrm{~km} /$ hour or $15 \mathrm{~km} /$ hour and give way rules reversed to give priority to pedestrians. Compliance with speed limits was encouraged by traffic calming measures such as speed humps. In addition, major roads passing through towns were also modified with the introduction in the 1980s of 'environmentally adapted through roads' which again used traffic engineering measures to reduce speed. These projects had a dramatic effect on safety and were also popular with residents. ${ }^{9}$ Similarly in Sweden, environmental modifications were implemented according to the SCAFT environmental planning guidelines which emphasised the importance of separating pedestrians from traffic. ${ }^{10}$

By contrast in New Zealand and Britain the major thrust of preventive strategy comprised attempts of change child behaviour through pedestrian skills training programmes. These programmes, however, have proved to be of limited value. ${ }^{11}$ Although a small scale evaluation in New Zealand did demonstrate changes in behaviour after pedestrian skills education, few programmes internationally have been shown to lead to reduced injury rates. ${ }^{12}{ }^{13}$ Indeed there is evidence to suggest that the fall in pedestrian mortality which occurred in New Zealand between 1974 and 1982 was due to the reduced growth in traffic volume after the oil crisis, rather than being the result of education campaigns. ${ }^{14}$

The international differences in pedestrian mortality cannot be taken as evidence for the efficacy of environmental prevention strategies as there may be other confounding factors, such as international differences in children's exposure to traffic, that account for them. Nevertheless, they do provide some support for the view that greater emphasis should be given to environmental approaches in future prevention efforts. ${ }^{8}$ These approaches will require expertise outside the domain of the paediatrician, in particular that of town planners and civil engineers. However paediatricians have an integral part to play in forging the interdisciplinary coalitions required to achieve these goals.

Thanks to A Dillon of the Office of Population Censuses and Surveys (England and Wales), Tom Gelskov of the Danish 
Council of Road Safety Research, Yvonne Lonn of Statistics Sweden, Richard Waxweiler of the Centers for Disease Control, and the National Health Statistics Centre for providing the data.

1 Rivara FP. Child pedestrian injuries in the United States.

Am $\mathcal{F}$ Dis Child 1990;144:692-6.
2 Roberts I, Norton R, Hassall I. Child pedestrian injury 1978-1987. NZ Med f 1992;105:51-2.

3 Office of Population Censuses and Surveys. 1986 Mortality statistics. London: OPCS, 1988.

4 Gallagher SS, Finison K, Guyer B, Goodenough S. The incidence of injuries among 87,000 Massachusetts children and adolescents: results of the 1980-81 statewide childhood injury prevention program surveillance system. Am $\mathcal{J}$ Public Health 1984;74:1340-7.

5 Roberts IG, Streat SJ, Judson JA, Norton RN. Critical injuries in paediatric pedestrians. NZ Med $\mathcal{J}$ 1989;102: 247-8.

6 Crouchman M. Children with head injuries. BMF 1990;301: 1289-90.
7 Kjemtrup K, Herrstedt L. Speed management and traffic calming in urban areas in Europe: a historical view. Accid Anal Prev 1992;24:57-65.

8 Sibert JR. Accidents to children: the doctor's role. Education or environmental change? Arch Dis Child 1991;66:890-3.

9 Engel U, Thomsen LK Safety effects of speed reducing measures in Danish residential areas. Accid Anal Prev 1992; 24:17-28.

10 Köhler L, Jackson H. Traffic and children's health. Stockholm: The Nordic School of Public Health, 1987. NHV-Report 1987:2.

11 Grayson GB. The identification of training objectives: what shall we tell the children? Accid Anal Prev 1981;13:169-73.

12 Hemmingway WG. Evaluating the efficacy of the safe playing programme. Access to a range of accident risk areas within a New Zealand city. Hamilton: University of Waikato, 1985. (M Soc Sci thesis.)

13 Organisation for Economic Cooperation and Development. Traffic safety for children. Report prepared by an OEDC Traffic safety for children. Report prepared
scientific expert group, Paris, April 1983.

14 Roberts I, Marshall R, Norton R. Child pedestrian mortality and traffic volume in New Zealand. BMJ 1992;305:283.
D 